\title{
Economic performance analysis of seismic isolation, energy dissipation, and traditional seismic structures
}

\author{
Shu-jiang JIANG ${ }^{1}$, Shun-zhong $\mathrm{YAO}^{1 *}$ and De-wen $\mathrm{LIU}^{2}$ \\ ${ }^{1}$ College of Civil Engineering, Southwest Forestry University, Kunming 650000, Yunnan, China
}

\begin{abstract}
The construction of a new countryside requires a compr hensive improvement in the building standards of villages and towns, and the seismic resistance of buildings in earthquake-prone areas has attracted much attention. Due to the backward economic development of villages and towns, the development of seismic isolation structure and energy dissipation structure is hindered. To build houses with better seismic performance, the economic efficiency of seismic isolation and energy dissipation structures has become a matter of close concern to the local people and the government. This article compares the economic differences between the original seismic structure, the base isolation structure, and the seismic damping structure from the costs incurred during the entire life cycle of the building, and provides economic reference for the new rural seismic isolation building.
\end{abstract}

\section{Introduction to life cycle costs}

The design service life of a building is generally 50 years, and the following costs are generally incurred during the life cycle: direct construction costs, including construction, decoration, and purchase of various indoor equipment; indirect costs, that is, loss and maintenance during the life of the building Cost [1].

\subsection{Direct construction costs}

Analysis from the perspective of direct construction economic costs: The survey of existing seismic isolation structures in my country shows that the cost of seismic isolation structures is related to the fortification intensity, structure type and number of structures in the area [2].

The addition of seismic isolation supports to the seismic isolation structure increases the cost of the seismic isolation layer, strengthens the basement column, and other seismic isolation structure costs. The damping structure adds dampers to the floors, which increases the cost of the dampers. As a result of the seismic isolation design, the scope of foundation treatment can be reduced, the main structure of the building will be greatly reduced under earthquakes, the cross-section of the structure can be reduced, the connection of non-main structural components can be simplified, and the cost of a part of the structure can be reduced.

The design of the seismic isolation structure with more seismic isolation layers than the original seismic structure has increased the design cost by $0.1 \%$ to $0.5 \%$ [3]. The initial direct construction cost of the structure after adopting seismic isolation and damping measures is shown in the following C1 [4]:

\footnotetext{
* Corresponding author's e-mail: 1844095825@qq.com.
}

$$
\begin{aligned}
& C_{1}=C_{S}+C_{I-i s o}-C_{s d} \\
& C_{I-i s o}\left(I_{d}\right)=\beta\left(I_{d}\right) \times C_{S} \\
& \alpha\left(I_{d}\right)=C z\left(I_{d}\right) / C_{0}=\left[C s\left(I_{d}\right)-C_{0}\right] / C_{0}
\end{aligned}
$$

In the formula, the initial total cost of design and construction for the direct use of seismic measures without the use of seismic isolation measures; the increase in related costs for the use of seismic reduction and isolation measures; the reduction of the seismic design of the upper structure due to the use of seismic isolation measures to reduce the intensity of the design Expenses; the statistical results of the literature [4] show that the average $\beta$ (Id) in the fortified areas of 7,8 , and 9 degrees are $6.2 \%, 8.5 \%$, and $9.5 \%$, respectively. $\alpha(\mathrm{I} \mathrm{d})$ is the value of the increase coefficient of the seismic fortification cost of the structure. According to some statistics in my country, the increase in construction cost is $3 \%$ to $8 \%$ and $10 \%$ to $15 \%$ in the VII, VIII, and IX regions. , $25 \% \sim 40 \%$ [5].

The upper structure of the seismic isolation and damping building can reduce the seismic fortification intensity design. Under the same intensity, the beam column size and reinforcement of the upper structure of the seismic isolation technology are reduced, and the cost will be lower than that of the traditional seismic building . The cost saved by the upper structure after adopting the shock-absorbing and isolating device is expressed by $\mathrm{C}_{\text {sd }}[5]$ :

$$
C_{s d}\left(I_{d}^{*}\right)=\gamma\left(I_{d}^{*}\right) \times C_{0}
$$

In the formula, $\mathrm{I} * \mathrm{~d}$ is the intensity after the superstructure is reduced, and $\mathrm{I}^{*} \mathrm{~d}$ is the integer intensity, then $\gamma(\mathrm{I} * d)=\alpha(\mathrm{I} d)-\alpha\left(I^{*} d\right) . \mathrm{C}_{0}$ is the initial cost of the structure without considering the seismic fortification. 


\subsection{Inspection and maintenance costs}

In order to ensure the safe use of the structure, during the whole life cycle of the building structure, the cost of checking and repairing the building structure to achieve its original use function. Since anti-aging materials are added to the materials for the seismic isolation support and dampers, the aging speed is slow in daily use, and the service life is generally longer than the service life of the building. There is no need to check and replace the support and dampers, so The daily maintenance cost of the seismic isolation support and the damping damper can be ignored [6].

\subsection{Post-earthquake loss costs}

From a long-term perspective, consider the situation where the building structure encounters a large earthquake. The direct economic loss is the cost of the damage to the building itself, the loss of indoor equipment and furniture; the indirect economic loss refers to the loss of economic benefits caused by the loss of the use function after the building is destroyed. There are two main parts that cause direct damage to buildings under the action of earthquakes, the acceleration caused by the structure and the loss caused by the displacement.

\section{Economic comparison}

In this paper, an example of Xishuangbanna is used for analysis. A two-story light steel-wood-plastic residence with a building area of $172.2 \mathrm{~m}^{2}$ and a structural fortification intensity of 8 degrees. According to the market price of light steel, it is estimated to be 1,500 yuan per square meter, and the price of wood plastic is estimated to be 200 yuan per square meter. The actual estimated total price of the original structure is 300,000 yuan. tables 1 and 2 are the prices of seismic isolation bearings and shock dampers that are currently inquired about suitable for buildings, and are for reference only.

Tab3. Direct construction costs for each structure
Tab1. Isolation support price information table

\begin{tabular}{|c|c|c|c|}
\hline Name & LRB400 & LRB500 & LRB600 \\
\hline Price & 1500 & 2000 & 4000 \\
\hline
\end{tabular}

Tab2. Different dampers price information table

\begin{tabular}{|c|c|c|}
\hline Name & $\begin{array}{c}\text { BRB } \\
\text { support }\end{array}$ & $\begin{array}{c}\text { Metal mild steel } \\
\text { support }\end{array}$ \\
\hline Price & 6800 & 5500 \\
\hline
\end{tabular}

The economic analysis of the seismic isolation structure and the seismic damping structure is mainly due to the different devices used, indicating that the comparison of the purchase cost of the seismic isolation support and the seismic damping damper is an important link in the economic comparison. The number of seismic isolation supports used in the article is 16 , and the number of seismic dampers is 4 .

\subsection{Comparison of direct construction costs}

The total direct construction cost of the structure directly using traditional seismic measures is $C_{S}=300,000$ yuan; because the structure is simple, the design cost of the seismic isolation layer is $0.1 \%$, so the design cost is increased by 3 million yuan. The initial construction cost corresponding to the reduced fortification intensity of the upper structure after the use of seismic reduction and isolation technology is $C_{\mathrm{Sd}}=19,000$ yuan; other costs that increase the cost of the structure by adopting seismic reduction and isolation measures $\mathrm{C}_{\mathrm{I}}$-iso3 $=25,500$ yuan; and the seismic reduction and isolation structure The initial total cost $\mathrm{C}_{1}=\mathrm{C}_{\mathrm{S}}+\mathrm{C}_{\mathrm{I}-\text {-isol }}+\mathrm{C}_{\mathrm{I}-\text {-iso } 3}+0.03-\mathrm{C}_{\mathrm{Sd}}$; the additional cost of the original structure is $\mathrm{C}_{1}-\mathrm{C}_{\mathrm{S}}$. The direct construction costs of each structure are shown in table 3.

\begin{tabular}{|c|c|c|c|c|c|}
\hline Name & Price & Quantity & $\begin{array}{c}\text { Cost } \\
\mathbf{C}_{\text {I-iso }}\end{array}$ & $\begin{array}{c}\text { Initial total cost } \\
\mathbf{C}_{\mathbf{1}}\end{array}$ & Increased costs \\
\hline LRB400 & 1500 & 16 & 2.4 & 33.08 & 3.08 \\
\hline LRB500 & 2000 & 16 & 3.2 & 33.88 & 3.88 \\
\hline LRB600 & 4000 & 16 & 6.4 & 37.08 & 7.08 \\
\hline BRB support & 6800 & 4 & 2.72 & 33.40 & 3.40 \\
\hline $\begin{array}{c}\text { Metal mild } \\
\text { steel support }\end{array}$ & 5500 & 4 & 2.2 & 32.88 & 2.88 \\
\hline
\end{tabular}

It can be seen from Table 3 that the initial cost of the structure with the seismic isolation support and the shock absorption damper is increased compared with the original structure. According to the price of the support and the damper, the increase ratio of the original structure is also different. The cost of the five structures in the seismic isolation system was increased by $10.3 \%, 12.9 \%, 23.6 \%$, $12.9 \%$, and $16.9 \%$; the cost of the two structures in the system was reduced by $11.3 \%$ and $9.6 \%$.

\subsection{Comparison of Inspection and maintenance costs}

The maintenance cost of ordinary building structure is generally $2 \%$ of the initial cost, so the original structure inspection and maintenance cost $\mathrm{C}_{\mathrm{M}}=30 \times 2 \%=6$ thousand yuan. Seismic isolation structure and damping structure take into account the improvement of the safety factor of the upper structure, and the structural damage will be 
much smaller. This article takes $1 \%$ of the initial cost. The inspection and maintenance fees of each structure are shown in table 4.

Tab4. Inspection and maintenance fees for each structure

\begin{tabular}{|c|c|c|}
\hline Nane & $\begin{array}{c}\text { Initial total cost } \\
\mathbf{C}_{\mathbf{1}}\end{array}$ & $\begin{array}{c}\text { Inspection and } \\
\text { maintenance cost } \\
\mathbf{C}_{\mathbf{M}}\end{array}$ \\
\hline LRB400 & 33.08 & 0.3308 \\
\hline LRB500 & 33.88 & 0.3388 \\
\hline LRB600 & 37.08 & 0.3708 \\
\hline BRB support & 33.40 & 0.3340 \\
\hline Metal mild steel support & 32.88 & 0.3288 \\
\hline
\end{tabular}

It can be seen from table 4 that the inspection and maintenance costs of each support and dampers are reduced compared with the original structure, and the reduction ratio is between $3.8 \%$ and $4.9 \%$.

\subsection{Comparison of Post-earthquake loss costs}

In order to simplify this part of the calculation, the total loss ratio of the seismic isolation and the original structure is taken as $2.7 \%$ and $18.1 \%$ respectively in this paper [6], and the loss ratio of the damping structure is taken as $5.9 \%$. Assuming that the total indoor property value of the building is equal to the total cost of the building structure itself, the original structure loss value is: $\mathrm{C}_{\mathrm{L}}=30 \times 18.1 \%=54,300$ yuan. The post-earthquake loss value of each structure in the seismic isolation system and seismic reduction system is shown in table 5 .

Tab5. Post-earthquake loss of each structure

\begin{tabular}{|c|c|c|c|}
\hline Nane & $\begin{array}{c}\text { Initial total cost } \\
\mathbf{C}_{\mathbf{1}}\end{array}$ & Loss ratio (\%) & $\begin{array}{c}\text { Loss value after earthquake } \\
\mathbf{C}_{\mathbf{L}}\end{array}$ \\
\hline LRB400 & 33.08 & 2.7 & 0.893 \\
\hline LRB500 & 33.88 & 2.7 & 0.915 \\
\hline LRB600 & 37.08 & 2.7 & 1.00 \\
\hline BRB support & 33.40 & 5.9 & 1.97 \\
\hline $\begin{array}{c}\text { Metal mild steel } \\
\text { support }\end{array}$ & 32.88 & 5.9. & 1.94 \\
\hline
\end{tabular}

The original structure was damaged more severely under the action of a large earthquake, and the damage to the building structure and internal equipment caused a larger proportion. In Table 5, the post-earthquake loss value of each structure is calculated according to the loss ratio of the seismic isolation and damping system under the earthquake. Compared with the original structure, the post-earthquake loss cost of the seismic isolation system is reduced by $82 \%$ to $84 \%$. The loss of the structure after the earthquake is reduced by $64 \%$, and the loss of the seismic isolation system is reduced by $49 \%$ to $55 \%$ compared with the damping structure.

\section{3 conclusion}

Proportion of post-earthquake loss costs: compared with the original structure, the post-earthquake loss cost of the seismic isolation system is reduced by $82 \%$ to $84 \%$, and the post-earthquake loss cost of the seismic damping system is reduced by $64 \%$ compared with the original structure. The seismic isolation system is $49 \%$ lower than the damping structure. $\% \sim 55 \%$; and the life-cycle cost ratio: the total cost of the seismic isolation system is lower than that of the original structure by $4.8 \%$ and $2.5 \%$, the total cost of the seismic isolation system is lower than the original structure by $0.92 \%$ and $2.4 \%$, and the total cost of the seismic isolation system is lower than that of shock absorption The total cost of the system is reduced by $0.6 \% \sim 3.9 \%$. These data show that the economic efficiency of the seismic isolation structure is also better than that of the seismic isolation structure, providing some economic references for the promotion and use of seismic isolation buildings. 


\section{References}

1. Wang Haibiao, Wang Longfeng. Economic analysis of multi-story base isolation buildings[J]. ShanxiArchitecture, 2019,45(03):224-225.

2. Jin Yulong. Seismic analysis and isolation research of container quay crane structure[D]. Shanghai Jiaotong University, 2012.

3. Chu Qingqing, Gong Keqin. Technical and economic analysis of seismic isolation structure[J]. Building structure, 2010.

4. Dang Yu, Du Yongfeng, Bi Changsong. Economic analysis of earthquake-isolated buildings [J]. Seismic Engineering and Reinforcement, 2006(4): 37-40.

5. Ma Yuhong, Zhao Guifeng, Tan Ping, et al. Research on the lifetime cost of base-isolated structures[J]. Earthquake Engineering and Engineering Vibration, 2012, 32 (5): 178-185.

6. Li Zengxin, Dong Yu. Economic analysis of seismic isolation frame structure [A]. Engineering Construction and Design, 2014. 